\title{
CHARACTERIZATION OF ROAD TRAFFIC EXTERNALITIES IN AN INTERCITY CORRIDOR
}

\author{
CARLOS SAMPAIO, ELOÍSA MACEDO, MARGARIDA C. COELHO, JORGE M. BANDEIRA \\ Centre for Mechanical Technology and Automation (TEMA), University of Aveiro, Portugal
}

\begin{abstract}
This paper aims at evaluating road transport externalities in an intercity corridor taking into account the energetic and economic characterization of the available road transport modes: intercity bus, individual transport and shared mobility. One of the purposes of this analysis is to identify the external costs (EC) and private costs (PC) of each mode/route and to which extent the best environmental option can be also considered as the best economical option. Results show the intercity bus at full or half occupancy is the best option in terms of EC, followed by the shared mobility. Regarding the $\mathrm{PC}$, results suggest that the best option is the shared mobility along route 1 (motorway), followed by the intercity bus. When comparing both routes, route 1 has less PC than route 2 (national road). In order to reduce the overall environmental impacts of a transport system, one solution might be the reduction of the EC through an optimization of the PC, ensuring that the option with less EC is also the option with less PC, so that it can encourage users to choose routes and transport modes with less environmental impacts.

Keywords: externalities costs, intercity bus, intercity corridors, private costs, shared mobility.
\end{abstract}

\section{INTRODUCTION}

In the European Union, the transportation sector represents $33 \%$ of the energy consumption (2016) and is responsible for $21 \%$ of greenhouse gas (GHG) emissions [1]. In particular, in Portugal, and according to latest data of 2016, this sector remains the main driver of GHG emissions (24\%) and represents a major proportion of the final energy consumption (37\%) [2]. Road transport is by far the largest contributor to energy consumption and GHG emissions. In Portugal, rural roads and motorways represent 58\% of the total vehicle-kilometres travelled in 2014 [3]. It is therefore important to reduce the use of road vehicles by fostering the use of both public transport and shared mobility. Among the parameters that influence modal and route choice are price, travel time, frequency, comfort and personal safety, while environmental considerations seem to be discarded.

The main objective of this paper is to assess an intercity corridor from environmental, energetic and economic perspectives and for that purpose, all road transport modes available in the corridor are evaluated: individual transport, shared mobility and public transport (bus).

\section{LITERATURE REVIEW}

The topic of intercity corridors has been receiving attention in the past years, mainly the impacts that the intercity traffic has in the environment, as well as road pricing schemes for this type of roads $[4,5]$.

Recent studies showed the introduction of eco-routing strategies might be a good way to decrease the total emissions of intercity corridors [6]. Considering a multiobjective route optimization problem with environmental concerns, it is shown that distributing traffic with the objective of minimizing the overall impacts, a reduction of $9 \%$ in terms of environmental costs can be achieved with a small variation on travel times [6]. Moreover, studies show that within a travel time variation of just $10 \%$, it is possible to obtain carbon dioxide $\left(\mathrm{CO}_{2}\right)$ savings around $11 \%[7,8]$. Selection of routes with less environmental impacts can lead to 
overall emission savings [9]. Faster intercity routes lead to less fuel consumption and $\mathrm{CO}_{2}$ emissions but may imply an increase up to $150 \%$ in the emissions of other pollutants [10]. In the context of route choice with environmental concerns, the trade-offs between travel times and overall emissions should be studied [11]. A routing choice analysis involves studying driver behaviour and routing guidance or strategy is very important to assess the real effectiveness of new and future measures. Although a new system may reduce externalities associated with road transport, the measures may not be well seen by road users [12], as drivers are only willing to pay if they see benefits in it [13].

A study from the United States focused on the most commonly used intercity modes of transport (aircraft, intercity bus and passenger cars) shows the intercity bus is the most efficient mode of transport in terms of fuel usage and has the lowest per-passenger emissions for all the ranges of distance studied [14]. Intercity buses have great importance to persons with no car, being an economically viable, environmentally friendly and a socially inclusive mode of transport for long-distance travel [15].

However, very few studies have been devoted to considering shared mobility within intercity passenger transport context. Moreover, a comparison between public transport and individual/shared vehicles has not been discussed. The objective of this paper is to analyse and compare the external and private costs (EC and PC) of each transport mode and route. For that purpose, an intercity corridor in Centro Region, Portugal, linking the cities of Aveiro and Coimbra will be used as a case study. This assessment can be of potential interest to increase the attractiveness of transport modes and routes with fewer externalities associated.

\section{METHODOLOGY}

The methodology used in this study comprises the traffic characterization and the estimation of impacts, fuel consumption and economic characterization parts.

The first part is devoted to studying the mobility patterns in the intercity corridor between the cities of Aveiro and Coimbra, Centro Region of Portugal, and for that purpose, the Sustainable Urban Mobility Plan of Aveiro [16] is considered. Regarding the routes, those that are available for individual/shared mobility are obtained using Google Maps [17], while bus route is obtained from [18].

A second part involves estimating impacts and fuel consumption by using data related to distance and time travelled.

\subsection{Traffic characterization}

Coimbra is one of the main destinations for intercity trips from Aveiro. Almost 5\% of intercity trips from Aveiro have as destination Coimbra, being Coimbra the origin of around 3\% of the trips to Aveiro. In terms of the modal split, $68 \%$ of the trips are based on individual transportation and only $2 \%$ are using the intercity bus, being the remaining $30 \%$ by others means of transport [16].

In terms of individual transport by car, it is possible to obtain different routing options between Aveiro - Coimbra using Google Maps [17]. For this particular case, two different options were considered, one by national roads and the other by motorway. For the intercity bus, the values of travel time and distance were obtained in [18]. The travel time and distance of both modes of transport and for each route are presented in the information provided in Table 1 is retrieved from Google Maps [17]. It can be observed that the travel time may vary depending on the type of road. Both are similar when comparing the 
Table 1: Travel time and distance for each route (motorway and national road) between Aveiro and Coimbra for travelling by individual transport or bus.

\begin{tabular}{llll}
\hline Mode & Route & Travel time & Distance \\
\hline Car & Motorway (route 1) & $42 \mathrm{~min}$ & $58.4 \mathrm{~km}$ \\
Car & National (route 2) & $1 \mathrm{~h} \mathrm{6} \mathrm{min}$ & $57.1 \mathrm{~km}$ \\
Intercity bus & Motorway (route 1) & $45 \mathrm{~min}$ & $62.0 \mathrm{~km}$ \\
\hline
\end{tabular}

Origin-Destination Aveiro - Coimbra and Coimbra - Aveiro, so the values presented here are only for the first case.

The population grid affected by these routes is depicted in Fig. 1 .

From the results obtained regarding travel time, the route using the motorway yields lower travel times for individual transport, followed by a route using the bus (which also uses the motorway). In terms of population distributions, there is a high level of the population potentially exposed to traffic pollution in the national road, with an average of population density of $678 \mathrm{hab} / \mathrm{km}^{2}$, against an average of $517 \mathrm{hab} / \mathrm{km}^{2}$ in the surroundings of the motorway linking the two cities. Recent studies show the population density factor can change the route with better environmental performance [19] since the values of EC increase with more people potentially exposed.

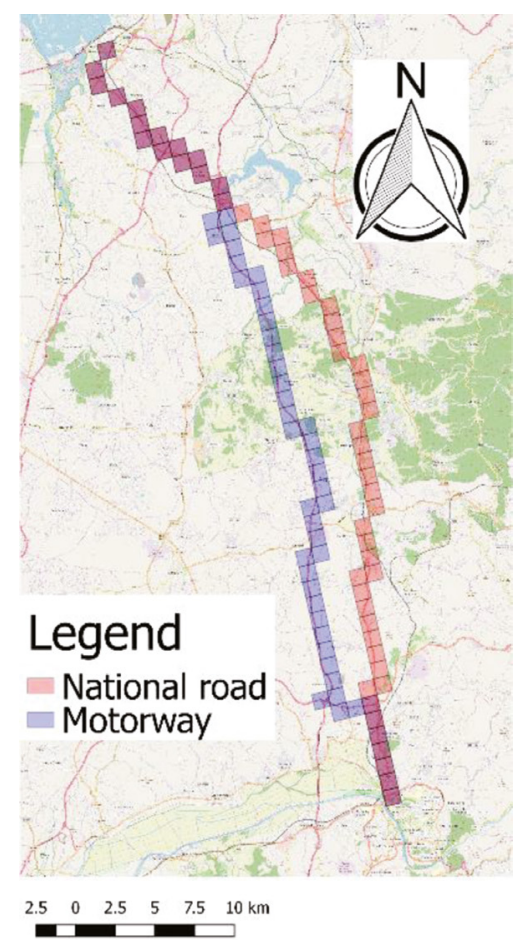

Figure 1: Road options and population affected represented in a $1 \times 1 \mathrm{~km}$ grid for each route considered between Aveiro and Coimbra. 


\subsection{Fleet characterization}

An energetic, economic and environmental characterization will be made between all the modes of road transport considered: individual transport, intercity bus and shared mobility. The vehicle technology that will be analysed is a EURO6 diesel/gasoline vehicle 1.4-2.0 L, and the intercity bus is a EURO6 $<=18$ ton, able to transport 52 passengers at full capacity. Different occupancy rates will also be evaluated (Table 2).

\subsection{Estimating Associated Costs}

The model used in this work to estimate pollutant emissions and fuel consumption is the COPERT4 [20], a widely used computer software in Europe. The pollutants under study are the $\mathrm{CO}_{2}$ (carbon dioxide), $\mathrm{NO}_{x}$ (nitrogen dioxides), NMVOC (non-methane volatile organic compound) and $\mathrm{PM}_{2.5}$ (particulate matter with a diameter of $2.5 \mu \mathrm{g}$ or less) and the externalities costs are estimated using the updated values reported in [21]. Table 3 displays the economic factor $(e c)$ values for Portugal. With respect to the impacts of local pollutants, population exposure is considered in the surroundings of each route based on the methodology recently described in [19]. The EC are estimated using the expression (1):

Table 2: Different occupancies simulated for each mode of transport.

\begin{tabular}{lcl}
\hline Mode & $\begin{array}{c}\text { Occupancy } \\
\text { (\#passengers) }\end{array}$ & Key \\
\hline Intercity bus & 10 & Bus low \\
Intercity bus & 26 & Bus half \\
Intercity bus & 52 & Bus full \\
Individual transport diesel & 1 & dPassenger_1 \\
Shared mobility diesel & 2 & dPassenger_2 \\
Shared mobility diesel & 3 & dPassenger_3 \\
Shared mobility diesel & 4 & dPassenger_4 \\
Individual transport gasoline & 1 & gPassenger_1 \\
Shared mobility gasoline & 2 & gPassenger_2 \\
Shared mobility gasoline & 3 & gPassenger_3 \\
Shared mobility gasoline & 4 & gPassenger_4 \\
\hline
\end{tabular}

Table 3: Economic factors for each pollutant for Portugal [21].

\begin{tabular}{lc}
\hline Pollutant & Economic factor (€/ton) \\
\hline $\mathrm{CO}_{2}$ & 90 \\
$\mathrm{NO}_{x}$ & 1,957 \\
$\mathrm{NMVOC}$ & 1,048 \\
$\mathrm{PM}_{2.5}$ & 196,335 \\
\hline
\end{tabular}




$$
E C=G P e c_{i}+\sum L P_{i} e c_{i} f,
$$

where $f=\frac{\overline{p d}}{1,500}$ is the adjustment factor related to average population density $\overline{p d}$ [19],ec is the economic factor for each pollutant $i$, GP is the global pollutant $\left(\mathrm{CO}_{2}\right.$, not affected by population density) given in ton and $L P_{i}$ denotes the local pollutant $i$ in ton.

An important component under costs is directly related to the user costs (UC), in which the average fuel and toll costs for individual transport should be taken into account.

From the passenger perspective, the costs associated with an intercity bus trip are related to the ticket price and for the shared mobility option, the average price presented at [22] is considered.

Furthermore, to calculate the PC, a methodology to estimate the value of (travel) time is used. The usage that the users do to their time while travelling is also an important factor [23]. It is proposed by [24] values of travel time cost for Portugal of $6.67 € / \mathrm{h}$ for the case of travelling by car, and $6.14 € / h$ in case of bus. Regarding the case of shared mobility, a special value is suggested to be included, an intermediate value of $6.41 € / \mathrm{h}$. Then, the PC can be given by:

$$
P C=U C+t t \times t f_{\text {mode }},
$$

where $t t$ is the travel time (h) and $t f_{\text {mode }}$ is the factor that represents the travel time cost per hour.

The average prices used in this study are presented in Table 4.

\section{RESULTS}

This section is devoted to presenting and discussing the results obtained for the mobility and route options considered in terms of fuel consumption, externalities and PC.

\subsection{Energetic characterization}

The results obtained for the energy characterization can be seen in the figure 2 . The results are represented by passenger.

The mode of transport that entails less fuel consumption is the bus at full capacity (Bus full), followed by the bus at half capacity (Bus half). The third mode of transport is shared mobility by diesel (gPassenger_4). As expected, the mode of transport with the highest fuel consumption is individual transport for both diesel and gasoline.

Table 4: Average UC prices (retrieved on 28 February 2019).

\begin{tabular}{lc}
\hline Intercity bus ticket [18] & $6 €$ \\
\hline Average diesel price [25] & $1,439 € / \mathrm{L}$ \\
Average gasoline price [25] & $1,545 € / \mathrm{L}$ \\
Toll price for the motorway option [26] & $2.6 €$ \\
Shared trip average price [22] & $5 €$ \\
\hline
\end{tabular}




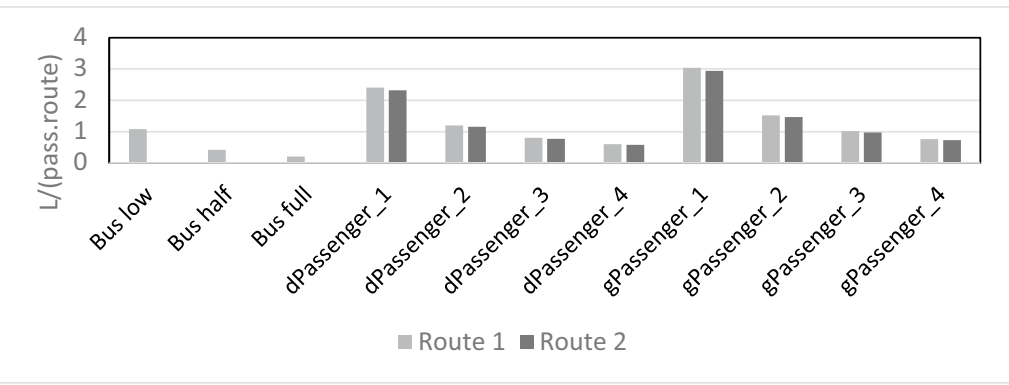

Figure 2: Fuel consumption by passenger for the different mobility solutions addressed.

When comparing both routes, the motorway (route 1) leads to higher fuel use when comparing to the national road (route 2). In all modes of transport, gasoline vehicles represent more fuel consumption than diesel vehicles.

\subsection{Environmental (external costs) characterization}

The table 5 displays the results regarding the EC for each mode and route.

The mode of transport with better results is the bus at full occupancy (Bus full), followed by the bus at half occupancy (Bus half). The third best performance is achieved by the shared mobility with 4 occupants (dPassenger_4 and gPassenger_4). When comparing both routes, route 2 (national road) entails less $0.6 \%$ of EC when a gasoline vehicle is used, while the route 1 (motorway) has better results when a diesel vehicle is used (EC $0.8 \%$ inferior). Comparing the diesel and gasoline vehicles, the former has on average $22 \%$ less of EC than the latter.

Regarding emissions, each pollutant represents different weights on the total emissions, as it can be observed in the figure 3. These results are for representative vehicles (Intercity Bus - "Bus"; Diesel Vehicle - "D_vehicle"; Gasoline Vehicle - "G_vehicle").

Table 5: EC results for each mode and route in $€$ per passenger.

\begin{tabular}{lcc}
\hline & Route 1 & Route 2 \\
\hline Bus empty & 3.777 & - \\
Bus low & 0.378 & - \\
Bus half & 0.145 & - \\
Bus full & 0.073 & - \\
dPassenger_1 & 0.864 & 0.860 \\
dPassenger_2 & 0.432 & 0.430 \\
dPassenger_3 & 0.288 & 0.286 \\
dPassenger_4 & 0.216 & 0.215 \\
gPassenger_1 & 1.121 & 1.130 \\
gPassenger_2 & 0.561 & 0.565 \\
gPassenger_3 & 0.373 & 0.377 \\
gPassenger_4 & 0.280 & 0.283 \\
\hline
\end{tabular}


a)

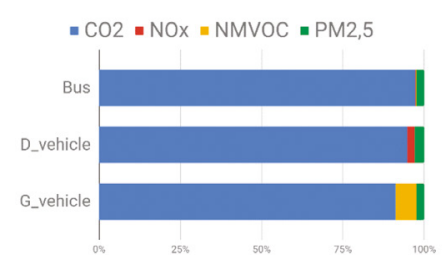

b)

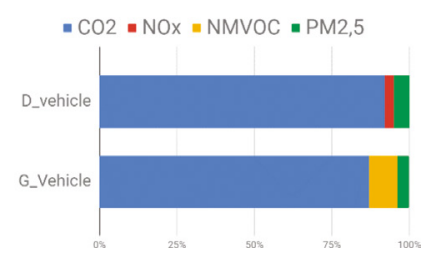

Figure 3: Weight of each pollutant for different vehicles: (a) route 1 and (b) route 2.

From this figure, it is possible to see that for both routes and all different vehicles the $\mathrm{CO}_{2}$ is the main contributor for the EC. Some differences can be highlighted between each type of vehicles. In particular, for the bus, $\mathrm{CO}_{2}$ represents almost $97 \%$ of the total $\mathrm{EC}$, being the remaining share divided by $2 \%$ for $\mathrm{PM}_{2.5}$ and $1 \%$ for both $\mathrm{NO}_{\mathrm{x}}$ and NMVOC. Regarding the $\mathrm{NO}_{\mathrm{x}}$ emissions, this pollutant represents some weight for the diesel vehicle $(2 \%)$ when compared to the gasoline vehicle, for which values are close to $0 \%$. NMVOC is a pollutant relevant in the gasoline vehicle with a share of $8 \%$ of the total costs, being practically $0 \%$ in the diesel vehicle. The emissions of $\mathrm{PM}_{2.5}$ are relevant in both vehicles, representing $4 \%$ and 3\% for diesel and gasoline, respectively, vehicles. These results also permit to conclude that $\mathrm{PM}_{2.5}$ has more weight in the route 2 (that has lower average speed), with an increase of $2 \%$ in the share of the total $\mathrm{EC}$ when compared to route 1 . In intercity trips, the $\mathrm{CO}_{2}$ usually represents a bigger weight than when urban trips are represented, because in urban environment there are more people potentially exposed. As the population density average is below $1,500 \mathrm{hab} / \mathrm{km}^{2}$, the population density factor makes the EC decrease for the local pollutants thus increasing the weight of $\mathrm{CO}_{2}$ and decrease the overall value of EC: Comparing the EC with and without the population density factor, it decreases. For route 1: 5\% for the bus, $9 \%$ for the diesel vehicle and $14 \%$ for the gasoline vehicle, and for route $2: 9 \%$ for the diesel vehicle and $13 \%$ for the gasoline vehicle.

\subsection{Economic (private costs) characterization}

The results in terms of PC obtained for the case study can be seen in Table 6. The PC includes the UC, which are the ticket for shared mobility and intercity bus, and fuel and toll (if applied) costs for the individual transport. The travel time costs are also included, which is important to know the perceived costs by the travellers and can be considered as an indicator that can be further used as a strategic indicator for road pricing with an objective of EC reduction [24] of a transport system such as an intercity corridor.

Table 6: PC results for each mode and route in $€$ per passenger.

\begin{tabular}{lcc}
\hline & Route 1 & Route 2 \\
\hline Intercity bus & 10.61 & - \\
Shared & 9.38 & 12.15 \\
Passenger vehicle (diesel) & 10.62 & 10.78 \\
Passenger vehicle (gasoline) & 11.85 & 11.98 \\
\hline
\end{tabular}



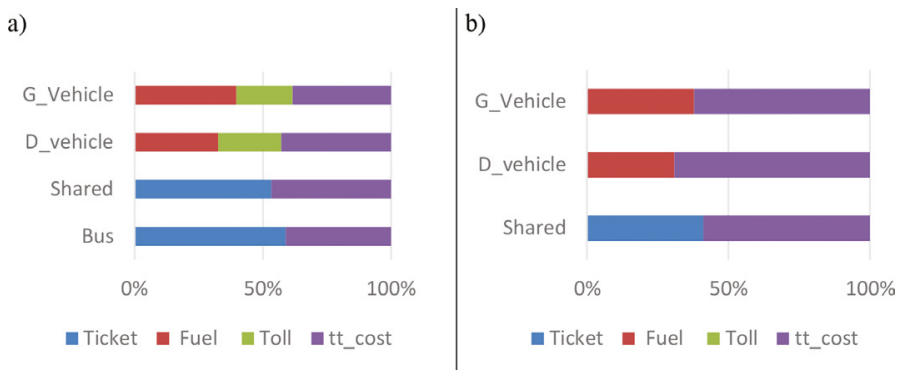

Figure 4: Disaggregation of the PC by ticket, fuel, toll and travel time cost (tt_cost) for each transport mode, and (a) route 1 and (b) route 2.

Results show the shared mobility through route 1 (motorway) is the cheapest option, followed by the intercity bus. When comparing both routes, route 1 has less PC than route 2 (national road).

In the figure 4, disaggregation of the PC by ticket, toll, fuel and travel time costs is presented.

For all vehicles, and in both routes, the travel time cost has major importance. This value should not be seen as a fixed constant, but involving some elasticity depending on the purpose and the travel time of the trip that may vary with different traffic conditions.

\section{CONCLUSIONS}

The main objective of this paper is to evaluate the impacts in terms of externalities of different road transport modes on an intercity corridor, and to perform an energetic and economic characterization of the corridor, taking into account the fuel consumption and the costs supported by the users.

Results show the bus with full or half occupancy as the transport mode with less energy consumption and externalities costs (EC), followed by the shared mobility with 4 occupants. For the PC, the option with less PC is the shared mobility through route 1 (motorway), followed by the intercity bus. When comparing both routes, route 1 has less PC than route 2 (national road). In particular, regarding the travel time costs that belong to a category of perceived costs, an average of $65 \%$ of the total PC in route 2 is due to travel time costs, against $45 \%$ in route 1.

Information regarding EC and PC may be very important because it can represent the perceived costs of the travellers. This allows a more efficient optimization of the routing options for better road pricing and awareness. Coupled with analyses of the trade-off between PC and EC, it allows developing new and better road pricing schemes based on minimizing EC. Results also show one transport mode/route may be more attractive in terms of PC but may be worse regarding EC. A set of possible solutions to influence people to adopt modes of transport with less EC is to provide guidance to make the choices on routes with less EC, but also with less PC, and by the introduction of for instance, dynamic toll prices, smart and dynamic ticketing for the intercity bus, incentive the high occupancy of the buses with more attractive prices, or fostering the use of shared mobility. 
Future research will be conducted on the following topics:

- Evaluate different options/scenarios, using different models and software, mainly focused on studying the elasticity involved in EC and PC;

- Regarding the EC, other externalities such as noise and traffic accidents can be included;

- Extend the study to include railroad transport.

\section{ACKNOWLEDGEMENTS}

The authors acknowledge the support of Strategic Project TEMA UID-EMS-0048-2013-FCT and CENTRO-01-0145-FEDER-022083, and projects: CISMOB (PGI01611), inFLOWence (POCI-01-0145-FEDER-029679), DICA-VE (POCI-01-0145-FEDER-029463), MobiWise (P2020 SAICTPAC/0011/2015) and "IDAD - Guyana energy inventory for the transportation sector". C. Sampaio also acknowledges the FCT support for the Scholarship SFRH/ BD/138746/2018.

\section{REFERENCES}

[1] Publications Office of the European Union (POEU). EU energy in figures : statistical pocketbook 2018. [Website], available at https://publications.europa.eu/en/publicationdetail/-/publication/99fc30eb-c06d-11e8-9893-01aa75ed71a1/language-en/formatPDF, 2018 (accessed 5 January 2019)

[2] Agência Portuguesa do Ambiente (APA). Relatório do Estado do Ambiente Portugal 2017, available at https://sniambgeoviewer.apambiente.pt/GeoDocs/geoportaldocs/ REA/REA2017/RelatorioEstadoAmbiente2017.pdf, 2017.

[3] EMISIA. COPERT Countries data, available at http://emisia.com/products/copert-data, 2015.

[4] Fontes, T., Pereira, S.R., Bandeira, J.M., \& Coelho, M.C., Assessment of the effectiveness of fuel and toll pricing policies in motorway emissions: an ex-post analysis. Research in Transportation Economics, 51, 83-93, 2015. DOI: 10.1016/j.retrec.2015.07.010.

[5] Bandeira, J., Coelho, M., Pimentel, M., \& Khattak, A., Impact of intercity tolls in portugal - an environmental perspective. Procedia - Social and Behavioral Sciences, $\mathbf{4 8 ,}$ 1174-1183, 2012. DOI: 10.1016/j.sbspro.2012.06.1093.

[6] Bandeira, J.M., Fernandes, P., Fontes, T., Pereira, S.R., Khattak, A.J., \& Coelho, M.C. Exploring multiple eco-routing guidance strategies in a commuting corridor. International Journal of Sustainable Transportation, 12(1), 53-65, 2018. DOI: 10.1080/15568318.2017.1328545.

[7] Zeng, W., Miwa, T., \& Morikawa, T., Prediction of vehicle $\mathrm{CO}_{2}$ emission and its application to eco-routing navigation. Transportation Research Part C: Emerging Technologies, 68, 194-214, 2016. DOI: 10.1016/j.trc.2016.04.007.

[8] Zeng, W., Miwa, T., \& Morikawa, T., Application of the support vector machine and heuristic k-shortest path algorithm to determine the most eco-friendly path with a travel time constraint. Transportation Research Part D: Transport and Environment, 57, 458473, 2017. DOI: 10.1016/j.trd.2017.10.001.

[9] Bandeira, J.M., Carvalho, D.O., Khattak, A.J., Rouphail, N.M., Fontes, T., Fernandes, P., ... Coelho, M.C., Empirical assessment of route choice impact on emissions over different road types, traffic demands, and driving scenarios. International Journal of Sustainable Transportation, 10(3), 271-283, 2016. DOI: 10.1080/15568318.2014.901447. 
[10] Bandeira, J., Almeida, T.G., Khattak, A.J., Rouphail, N.M., \& Coelho, M.C., Generating emissions information for route selection: experimental monitoring and routes characterization. Journal of Intelligent Transportation Systems, 17(1), 3-17, 2013. DOI: 10.1080/15472450.2012.706197.

[11] Nie, Y. (Marco) \& Li, Q., An eco-routing model considering microscopic vehicle operating conditions. Transportation Research Part B: Methodological, 55, 154-170, 2013. DOI: $10.1016 /$ j.trb.2013.06.004.

[12] Abdulsalam Bin Miskeen, M.A., Rahmat, R.A.A.B.O.K., \& Alhodairi, A.M., Modelling intercity route choice behaviour to explore road users' response to road pricing policy in Libya. Australian Journal of Basic and Applied Sciences, 6(9), 431-439, 2012.

[13] Soriguera, F., On the value of highway travel time information systems. Transportation Research Part A: Policy and Practice, 70, 294-310, 2014. DOI: 10.1016/j. tra.2014.10.005.

[14] Liu, H., Xu, Y. “Ann”, Stockwell, N., Rodgers, M.O., \& Guensler, R., A comparative life-cycle energy and emissions analysis for intercity passenger transportation in the U.S. by aviation, intercity bus, and automobile. Transportation Research Part D: Transport and Environment, 48, 267-283, 2016. DOI: 10.1016/j.trd.2016.08.027.

[15] Woldeamanuel, M., Evaluating the competitiveness of intercity buses in terms of sustainability indicators. Journal of Public Transportation, 15(3), 77-96, 2012. DOI: 10.5038/2375-0901.15.3.5.

[16] WAY2GO, Plano Municipal de Mobilidade de Aveiro, available at http://files.cm-aveiro.pt/XPQ5FaAXX42842aGdb9zMjjeZKU.pdf, 2012.

[17] Google, Google Maps, available at https://www.google.com/maps, 2019.

[18] Rede expressos, Rede expressos, available at https://www.rede-expressos.pt/, 2019 (accessed 28 February 2019).

[19] Sampaio, C., Bandeira, J.M., Macedo, E., Vilaça, M., Guarnaccia, C., Friedrich, B., ... Coelho, M.C., A Dynamic Link-based Eco-indicator for supporting equitable traffic management strategies. Transportation Research Procedia, 37, 43-50, 2019. DOI: 10.1016/j.trpro.2018.12.164.

[20] EMISIA, COPERT4 [Computer Software], available at https://www.eea.europa.eu/ data-and-maps/data/external/copert-4, 2016.

[21] Korzhenevych, A., Bröcker, J., Holtkamp, H.M., Gibson, G., Varma, A., \& Cox, V., Update of the Handbook on External Costs of Transport, available at https://ec.europa. eu/transport/sites/transport/files/handbook_on_external_costs_of_transport_2014_0. pdf, 2014.

[22] BlaBlaCar, Viagens Aveiro -> Coimbra, available at https://www.blablacar.pt, 2019 (accessed 28 February 2019).

[23] Kouwenhoven, M., \& de Jong, G., Value of travel time as a function of comfort. Journal of Choice Modelling, 28, 97-107, 2018. DOI: 10.1016/j.jocm.2018.04.002.

[24] Wardman, M., Chintakayala, P., de Jong, G., \& Ferrer, D., European wide meta-analysis of values of travel time, available at http://www.significance.nl/papers/2012-European\%20wide $\% 20$ meta-analysis $\% 20$ of\%20values $\% 20$ of $\% 20$ travel\%20time.pdf, 2012.

[25] Maisgasolina, Preços médios dos combustíveis, available at https://www.maisgasolina. com/, 2019 (accessed 28 February 2019).

[26] ViaMichelin, Itinerários Aveiro -> Coimbra, available at https://www.viamichelin.pt, 2019. 